\title{
Erratum
}

\section{Pleurotus sajor-caju HSP100 complements a thermotolerance defect in hsp104 mutant Saccharomyces cerevisiae}

Jin-Ohk Lee, Mi-Jeong Jeong, Tack-Ryun Kwon, Seung-Kon Lee, Myung-Ok Byun, Ill-Min Chung and Soo-Chul Park 2006, J. Biosci., 31, 223-233

The following corrections require to be made in the printed version of the above article. These corrections will appear in print in the September 2006 issue.

(1) Ill-Min Chung is a joint corresponding author. His fax and email are: Fax, 82-2-446-7856; and Email, imcim@konkuk.ac.kr.

(2) The statement "Jin-Ohk Lee and Mi-Jeong Jeong contributed equally to this paper" was mistakenly left out from the 'Acknowledgements'. It will be included now. 